\title{
Path, Portal, Place sebagai Strategi Penguat Karakter Aksesibilitas Wisata Candi Plaosan
}

Desrina Ratriningsih ${ }^{\mathrm{a},{ }^{*}}$, Wiliarto Wirasmoyo ${ }^{\mathrm{b}}$, Akbar Preambudic

${ }^{\mathrm{a}, \mathrm{b}, \mathrm{c}}$ Program Studi Arsitektur, Universitas Teknologi Yogyakarta, Yogyakarta, Indonesia

Keywords:

Cultural tourism

Plaosan Temple

Path, Portal, Place
Kata kunci:

Wisata Budaya

Candi Plaosan

Path, Portal, Place

\begin{abstract}
Cultural tourism is a type of tourist attraction object based on the work of human creativity in the form of cultural heritage and cultural values that are still lively today. In the Klaten Regency Spatial Plan 2011-2031. Plaosan Lor Temple and Plaosan Kidul has been designated as a Cultural Conservation site as a tourist area, especially temple tourism with Prambanan Temples, Sojiwan Temples, Bubrah Temples, Lumbung Temples, Sewu Temples, Asu/Gana Temples, and Lor/Candirejo Temples. The development of a tourist attraction based on attraction must be supported by the component of accessibility and facilities, accessibility makes it easy for visitors to reach a tourist attraction while the facilities can meet the needs of visitors as long as they enjoy the attractions in a tourist attraction of their choice. The problem with reaching the Plaosan Temple tourist complex is the lack of wayfinding to reach the area. The research method used is using a qualitative rationalistic research framework, which focuses on individual perceptions in seeing, understanding and analyzing the concept of Path, Portal, Place in the Plaosan temple tourist area. This research begins with direct observation, including physical observations and activities based on the parameters and indicators that are formulated. Field observations include physical and activity observations. The results of the study are in the form of directions that can strengthen the achievement of accessibility to the Plaosan Temple tourist complex in order to improve the quality as one of the temple tourism destinations
\end{abstract}

\section{ABSTRAK}

Pariwisata budaya adalah jenis obyek daya tarik wisata yang berbasis pada hasil karya cipta manusia baik yang berupa peninggalan budaya maupun nilai budaya yang masih hidup sampai sekarang. Di dalam Rencana Tata Ruang Wilayah Kabupaten Klaten tahun 20112031. Candi Plaosan Lor dan Plaosan Kidul sudah ditetapkan menjadi situs Cagar Budaya menjadi satu kawasan wisata khususnya wisata candi dengan Candi Prambanan, Candi Sojiwan, Candi Bubrah, Candi Lumbung, Candi Sewu, Candi Asu/Gana, dan Candi Lor/Candirejo. Pengembangan suatu objek wisata dengan basis atraksi harus didukung oleh komponen aksibilitas dan fasilitas, aksebilitas memberikan kemudahan kepada pengunjung untuk menjangkau suatu objek wisata sementara fasilitas dapat memenuhi kebutuhan pengunjung selama mereka menikmati atraksi di suatu objek wisata yang dipilihnya. Permasalahan terhadap pencapaian menuju Kompleks wisata Candi Plaosan adalah minimnya penanda untuk mencapai kawasan. Metode penelitian yang digunakan adalah menggunakan kerangka penelitian rasionalistik kualitatif, yang berfokus pada persepsi individu dalam melihat, memahami dan menganalisis konsep Path, Portal, Place pada kawasan wisata candi Plaosan. Penelitian ini dimulai dengan pengamatan secara langsung, meliputi amatan fisik dan aktivitas berdasarkan parameter dan indikator yang di rumuskan. Pengamatan lapangan meliputi amatan fisik dan aktivitas. Hasil penelitian berupa arahan yang dapat memperkuat pencapaian aksesibilitas menuju Kompleks wisata Candi Plaosan agar dapat meningkatkan kualitas sebagai salah satud estinasi wisata Candi.

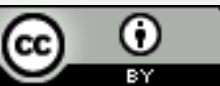

This is an open access article under the CC-BY license. 


\section{Pendahuluan}

\subsection{Candi Plaosan sebagai Destinasi Wisata Candi}

Pariwisata budaya adalah jenis obyek daya tarik wisata yang berbasis pada hasil karya cipta manusia baik yang berupa peninggalan budaya maupun nilai budaya yang masih hidup sampai sekarang [1]. Wujud dari wisata budaya ini antara lain museum, candi dan acara adat. Candi Plaosan terletak di Desa Bugisan, Kecamatan Prambanan, Kabupaten Klaten, kira-kira 1,5 km ke arah timur dari Candi Sewu. Candi Plaosan merupakan Candi Buddha yang dibangun saat pemerintahan Raja Rakai Pikatan. Seluruh kompleks Candi Plaosan memiliki 116 stupa perwara dan 50 candi perwara. Stupa perwara bisa dilihat di semua sisi candi utama, demikian pula candi perwara yang ukurannya lebih kecil.
Di dalam Rencana Tata Ruang Wilayah Kabupaten Klaten tahun 2011-2031 Candi Plaosan Lor dan Plaosan Kidul sudah ditetapkan menjadi situs Cagar Budaya menjadi satu kawasan wisata khususnya wisata candi dengan Candi Prambanan, Candi Sojiwan, Candi Bubrah, Candi Lumbung, Candi Sewu, Candi Asu/Gana, dan Candi Lor/Candirejo [2].

Candi ini merupakan sebuah kompleks bangunan kuno yang terbagi menjadi dua, yaitu kompleks Candi Plaosan Lor (lor dalam bahasa Jawa berarti utara) dan kompleks Candi Plaosan Kidul (kidul dalam bahasa Jawa berarti selatan). Kedua kompleks Candi dipisahkan oleh jalan aspal yang memebentang timur barat dan lingkungan tanah persawahan. Pada masa lalu, kompleks percandian ini dikelilingi oleh parit berbentuk persegi panjang. Sisa struktur tersebut masih bisa dilihat sampai saat ini di bagian timur dan barat candi.
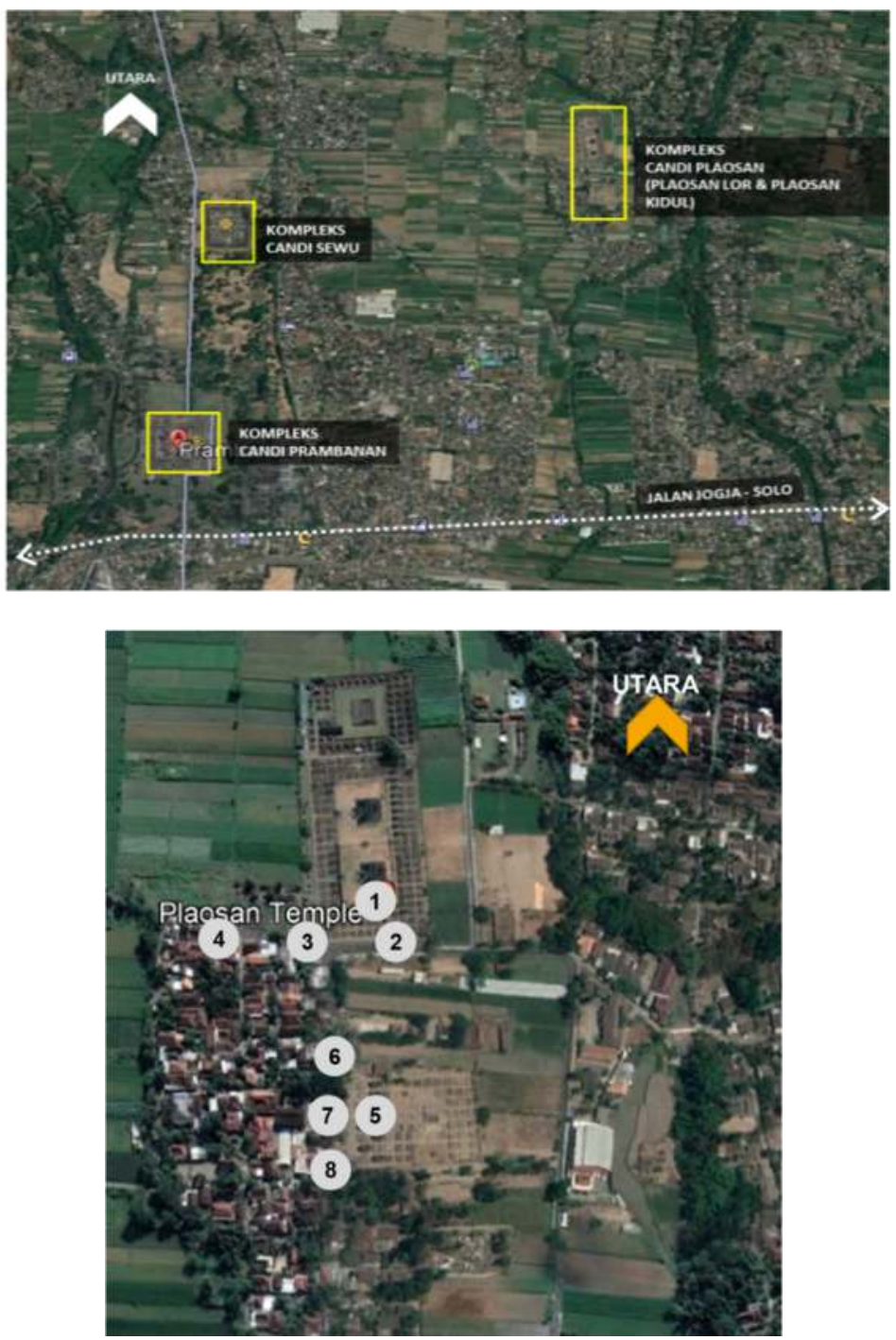

Gambar 1 Lokasi Kompleks Candi Plaosan 


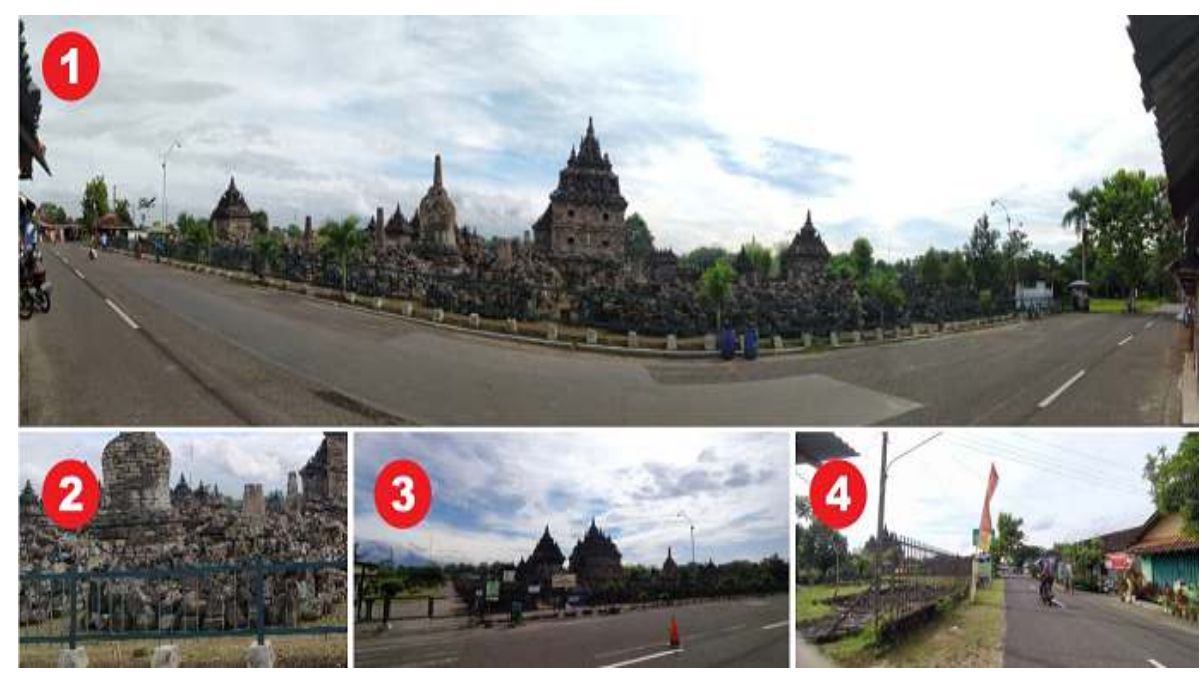

Gambar 2. Eksisting Candi Plaosan Lor

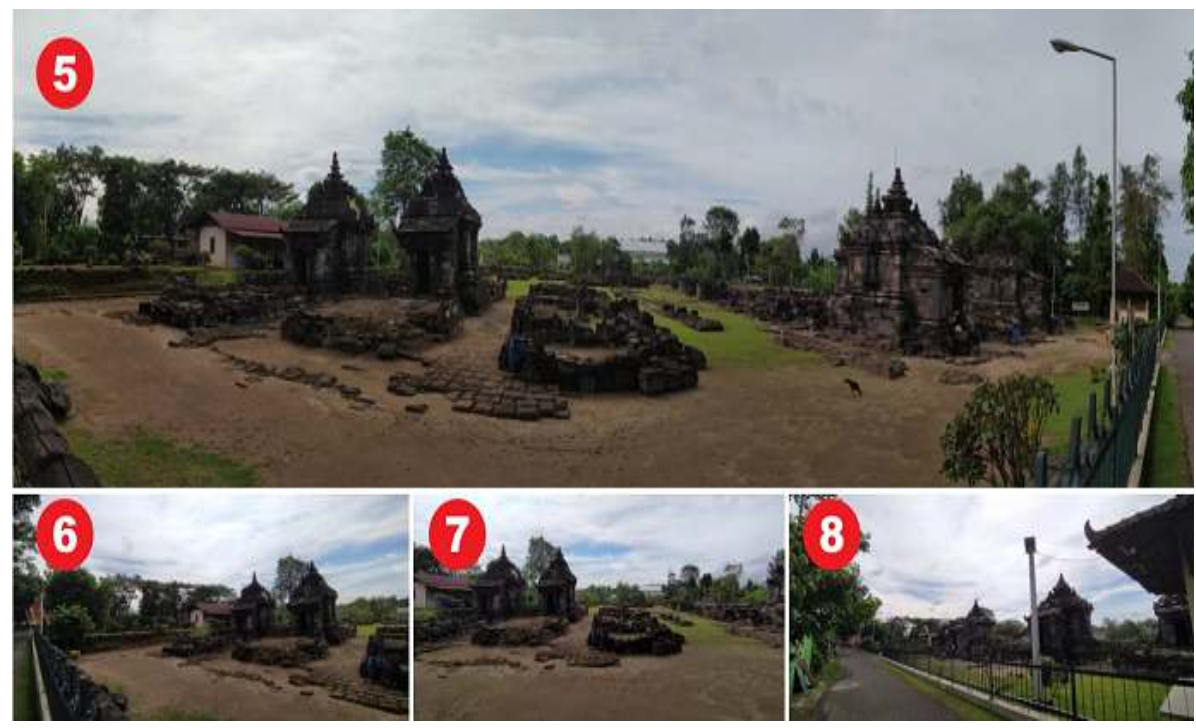

Gambar 3. Eksisting Candi Plaosan Kidul

Gambar 2, kondisi eksisting Candi Plaosan Lor lebih besar dari pada Candi Palosan Kidul (view1). Pintu masuk kawasan Candi Plaosan berada di sebelah sisi barat (view 2). Kondisi kawasan candi sebelah barat banyak digunakan untuk proses penggalian arkeologis (view 3). Gambar 3, kondisi eksisting Candi Plaosan Kidul dari arah barat (view 4, 5, dan 6).

Selain bangunan Candi, Kompleks Candi Plaosan memiliki potensi budaya berupa Festival Candi kembar. Merupakan rangkaian kegiatan budaya yang dilaksanakan setiap tahun sekali, salah satunya berupa Kirab Budaya yang diikuti 8 RW di Desa Bugisan, masing-masing menampilkan kreasi lewat kostum, hasil bumi, hingga musik. Arak-arakan dimulai dari Candi Sewu dan berakhir di sisi timur Candi Plaosan Lor.

Sebagai salah satu objek Wisata Candi yang telah ditetapkan oleh pemerintah, Kompleks Candi Plaosan tidak seramai kompleks candi yang lain, seperti Candi Sewu, Candi Prambanan dan candi Ratu Boko. Hal ini didasarkan pada hasil penelitian oleh Indriyani [3] diperoleh hasil identifikasi potensi wisata Candi yang terdapat di Klaten ada pada Tabel 1.

Dari hasil skoring, Kompleks Candi Plaosan memiliki potensi untuk berkembang agar tidak kalah dari wisata candi yang lain. Beberapa permasalahan di Kompleks Candi Plaosan yang perlu dicermati yaitu kurangnya sarana informasi tentang Candi Plaosan sementara candi tersebut kondisinya telah layak untuk dimanfaatkan secara lebih. Selain itu, kondisi dan pemanfaatan terkait pengolahan aksesibilitas dan kelengkapan amenitas Kompleks Candi Plaosan belum dilaksanakan secara optimal. 
Tabel 1. Hasil Skoring dan Klasifikasi Potensi Internal Obyek Wisata Candi di Kabupaten Klaten Tahun 2018

\begin{tabular}{llllr}
\hline \multirow{4}{*}{ Obyek wisata candi } & \multicolumn{5}{c}{ Kualitas obyek } \\
& A & B & C & D \\
\hline Candi Sewu & 2 & 3 & 3 & 2 \\
Candi Lumbung & 2 & 3 & 3 & 2 \\
Candi Bubrah & 2 & 3 & 3 & 2 \\
Candi Plaosan Lor & 2 & 2 & 2 & 2 \\
Candi Plaosan Kidul & 1 & 1 & 2 & 2 \\
Candi Sojiwan & 1 & 1 & 2 & 2 \\
Candi Merak & 1 & 1 & 1 & 2 \\
Keterangan: & & & & \\
A : Daya tarik obyek wisata & \\
B : Keragaman atraksi atau daya tarik pendukung \\
C : Potensi pengembangan \\
D : Kondisi fisik obyek wisata \\
E : Kebersihan lingkungan obyek wisata
\end{tabular}

\subsection{Permasalahan Aksesibilitas menuju Candi Plaosan}

Pengembangan objek wisata dengan basis atraksi yang baik harus didukung oleh komponen aksibilitas dan fasilitas. Sebagaimana pada [4] yang berpendapat bahwa berhasilnya suatu tempat wisata hingga tercapainya kawasan wisata sangat tergantung pada $3 \mathrm{~A}$ yaitu atraksi (attraction), mudah dicapai (accessibility), dan fasilitas (amenities).

Aksebilitas memberikan kemudahan kepada pengunjung untuk menjangkau suatu objek wisata sementara fasilitas dapat memenuhi kebutuhan pengunjung selama mereka menikmati atraksi di suatu objek wisata yang dipilihnya.

Di dalam pendapat yang dikemukan oleh [5] menyatakan bahwa aksesibilitas merupakan salah satu aspek penting yang mendukung pengembangan sebuah objek wisata. Suatu objek wisata merupakan akhir dari perjalanan wisata, artinya objek wisata harus mudah dicapai dan dapat ditemukan dengan mudah. Selain itu, mengungkapkan bahwa persyaratan aksesibilitas terdiri atas kemudahan informasi, mudah dicapai dan ditemukan, memiliki kondisi jalan yang baik, memiliki kenyamanan secara visual dan dapat dilalui.

Menurut pandangan [6] kenyamanan secara visual dijelaskan sebagai berikut: View, mencakup aspek estetis dengan aplikasi terhadap estetika jalur pedestrian sebagai elemen fisik kota. Identity, mencakup karakter, definisi ruang, ekspresi terhadap semua elemen estetika, kejadian (event) dan nilai yang membuat jelas secara panglihatan, dengan apikasinya terhadap kejelasan identitas jalur pedestrian melalui elemen-elemen, baik street furniture maupun kondisi fisik jalur pedestriannya (dimensi, material, warna dan sebagainya).

Untuk menuju kawasan Candi Plaosan, dari arah Jalan Raya Yogya-Solo ke utara melalui Jalan PrambananManisrenggo sejauh kurang lebih 1,5 km kemudian berbelok kea rah Timur menuju Jalan Candi Plaosan sejauh kurang lebih 500 m Gambar 4. 


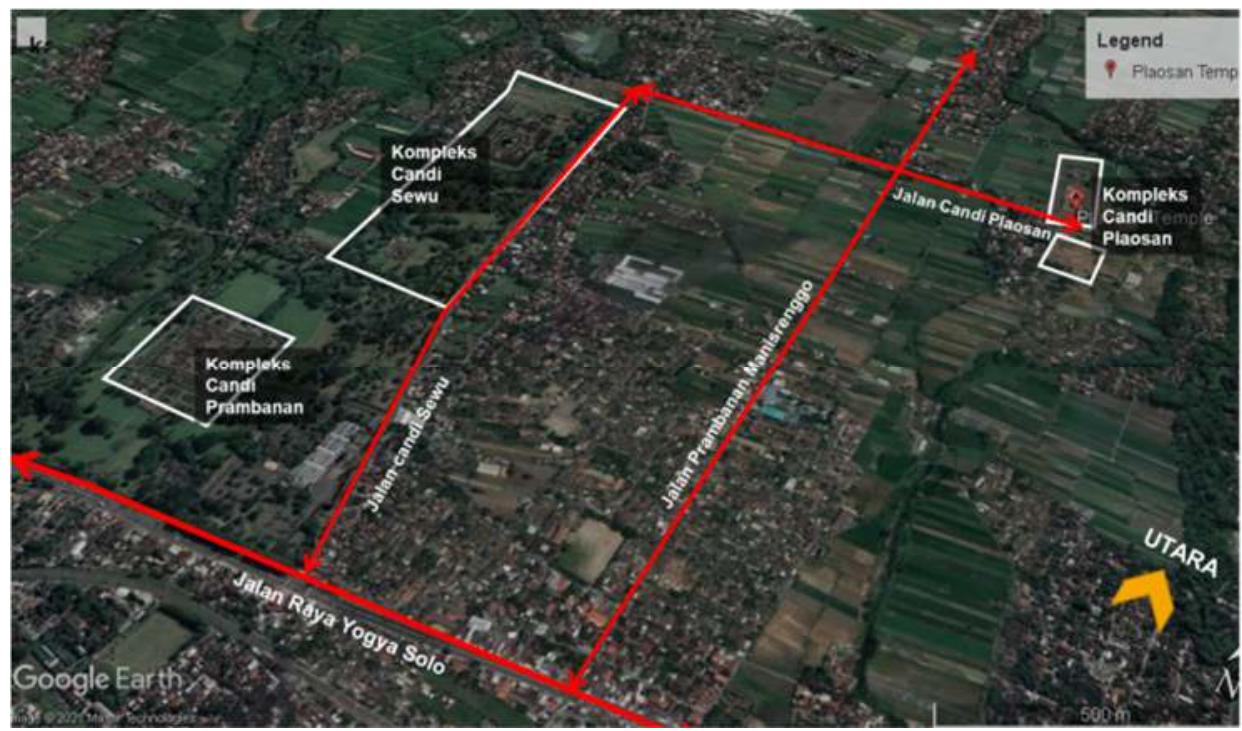

Gambar 4. Pencapaian ke kompleks Candi Plaosan

\subsection{Konsep Path, Portal, Place}

Path, portal dan place adalah merupakan salah satu strategi untuk mendesain ruang luar di suatu tatanan perkotaan agar memiliki makna ruang atau tempat tersebut. Desain path, portal dibuat linier dan mengarahkan ke Place [7].

Path lebih cenderung berupa sebuah jalur linear dan berfungsi sebagai jalur sirkulasi berpindah menuju suatu place atau dari place ke place yang lain. Secara mudah dapat dikenali karena merupakan koridor linier yang dapat dirasakan oleh manusia pada saat berjalan mengamati kota. Ruang jalan yang berhasil dapat ditinjau dari sebanyak apa indra kita (sensory) merespon. Visual yang bagus, tekstur atau material yang bisa disentuh, atau aroma dan bau yang dapat dirasakan indra manusia.

Pengalaman ruang, ragam aktivitas yang terjadi dan kemudahan akses menjadi poin utama sebuah path. sebuah path biasanya terkait dengan sebuah cerita yang diwujudkan ke dalam elemen fisiknya sehingga dapat mewujudkan identitas suatu tempat.Kemampuan menangkap identitas kota sangat subyektif, tergantung si pengamat, yang menarik secara visual (jelas, terbaca, atau terlihat) dan mudah diingat serta memiliki keunikan untuk dijadikan sebagai identitas kawasan.
Path dapat membentuk image yang kuat jika mengarah pada suatu destinasi yang penting (menuju stasiun, tugu, alun-alun, dsb), memiliki pelingkup ruang jalan yang spesifik (dominasi fasade bangunan, pepohonan, dsb), terdapat beberapa bagian penting kota (tempat, bangunan, dan sebagainya) di sepanjang ruang jalan[8]

Portal merupakan batas dan transisi antara area publik dan privat. Portal biasanya juga merupakan batas berubahnya ambience(suasana). Posisi Portal biasanya mendekati Place.

portal yang berhasil didasarkan pada keberhasilannya dalam menghubungkan path dengan place. Dapat dengan benar benar menjadi batas yang memisahkan dua suasana yang berbeda.

Place adalah space yang memiliki makna atau identitas kuat. Terdapat tiga kriteria suatu tempat layak dikatakan menjadi sebuah place, yaitu kemenarikan fisik terbangun, fungsi atau aktivitas yang mendukung dan citra/budaya.

Suatu tempat wisata dapat dikatakan berhasil apabila kawasan tersebut hidup dengan kegiatan wisata dan kelengkapan sarana pendukungnya, serta dapat membuat pengunjung atau wisatawan betah berlama-lama dan memiliki keinginan untuk mengunjungi kembali kawasan wisata tersebut [9]. 


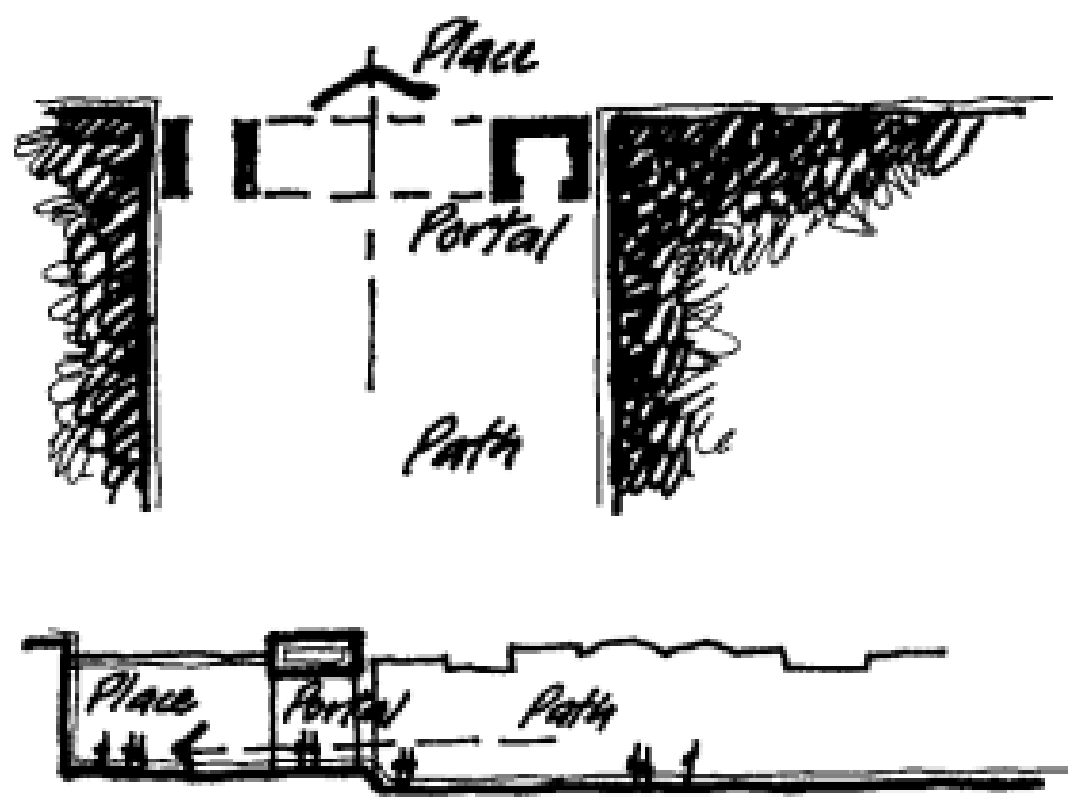

Gambar 5. Tinjauan Path, Portal, Place

\section{Metode}

Penelitian ini dilakukan di kompleks Candi Plaosan, mulai dari jalan Raya Yogya-Solo mengarah ke Candi
Plaosan Lor dan Plaosan Kidul, meliputi akses menuju Candi, jenis penanda yang ada dan pencapaian ke kawasan.

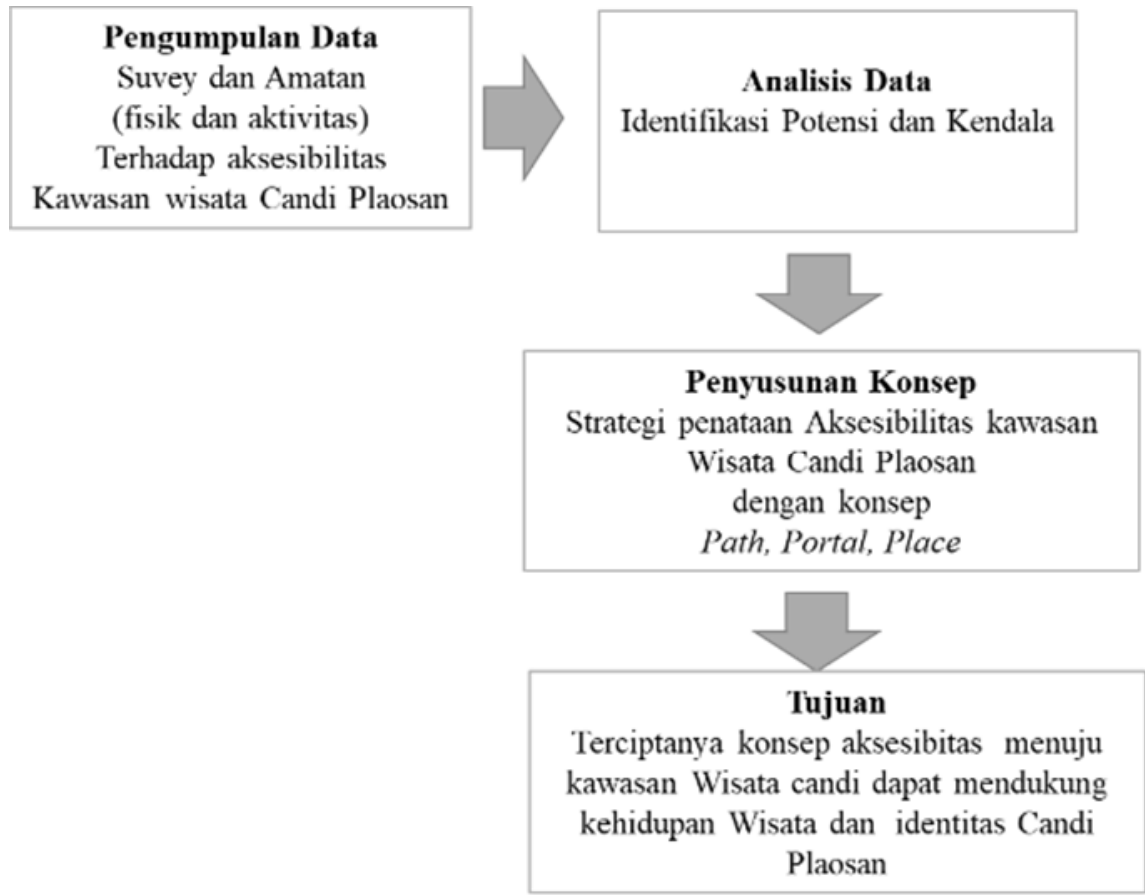

Gambar 6. Kerangka pikir penelitian

Metode penelitian yang digunakan adalah Penelitian ini menggunakan kerangka penelitian rasionalistik kualitatif, yang berfokus pada persepsi individu dalam melihat, memahami dan menganalisis kondisi aksesibilitas pada kawasan Candi Plaosan. Menemukan potensi dan masalah dari hasil temuan. Setelah itu, merumuskan konsep Path, Portal, Place pada kawasan wisata candi Plaosan sebagai solusi. Penelitian ini dimulai dengan pengamatan secara langsung, meliputi amatan fisik dan aktivitas berdasarkan parameter dan indikator yang di rumuskan. Pengamatan lapangan meliputi amatan fisik dan aktivitas. 
Table 2. Parameter Amatan Aksesibilitas

\begin{tabular}{|c|c|c|c|}
\hline Kemudahan & & ignage/penanda & Ada \\
\hline \multirow[t]{4}{*}{ Pencapaian } & & Jarak & Semakin dekat dari pus \\
\hline & Dim & nensi dan Material & Sesuai/tidak c \\
\hline & Ketersedi & iaan Sarana transportasi & Ada \\
\hline & & Umum & \\
\hline \multirow{6}{*}{$\begin{array}{c}\text { Kemenarikan Jalur } \\
\text { (attractiveness) }\end{array}$} & & Street Furniture & Ada atau \\
\hline & & Jalur Pedestrian & Ada \\
\hline & & & Terhubun \\
\hline & & aterial dan warna & Ada \\
\hline & & italitas Kawasan & Ada/tidak aktivitas pada \\
\hline & & egetasi peneduh & Ada \\
\hline \multirow[t]{26}{*}{ Legibilitas } & Titik & k Masuk/ Gerbang & Ada/ \\
\hline & & Signage/ & Ada \\
\hline & & penanda & \\
\hline & Titil & k berhenti (nodes) & Ada \\
\hline & & Identity/ & Kua \\
\hline & & karakter ruang & \\
\hline & \multicolumn{3}{|c|}{ Tabel 3. Parameter Konsep Path, Portal, Place } \\
\hline & \multirow{13}{*}{ Path } & Signage/penanda & \\
\hline & & Dimensi dan Material & \\
\hline & & Ketersediaan Sarana tr & ortasi Umum \\
\hline & & Street Furniture & \\
\hline & & Jalur Pedestrian & \\
\hline & & Material dan warna & \\
\hline & & Vitalitas Kawasan & \\
\hline & & Vegetasi peneduh & \\
\hline & & Titik Masuk/ Gerbang & \\
\hline & & Titik berhenti (nodes) & \\
\hline & & Identity/ & \\
\hline & & karakter ruang & \\
\hline & & Signage/penanda & \\
\hline & \multirow{3}{*}{ Portal } & Ketersediaan Sarana tr & ortasi Umum \\
\hline & & Identity/ & \\
\hline & & karakter ruang & \\
\hline & \multirow[t]{3}{*}{ Place } & Identity/ & \\
\hline & & karakter ruang & \\
\hline & & Vitalitas Kawasan & \\
\hline
\end{tabular}

Rekomendasi penelitian ini adalah tercapainya ruang jalan yang sesuai dengan konsep path, portal place sehingga dapat menciptakan keterbacaan akses menuju ke kawasan wisata Candi Plaosan.

\section{Hasil}

\subsection{Kemudahan Pencapaian Aksebilitas}

Untuk menuju kawasan Candi Plaosan, dari arah Jalan Raya Yogya-Solo ke utara melalui Jalan PrambananManisrenggo sejauh kurang lebih 1,5 km kemudian berbelok kea rah Timur menuju Jalan Candi Plaosan sejauh kurang lebih $500 \mathrm{~m}$. 

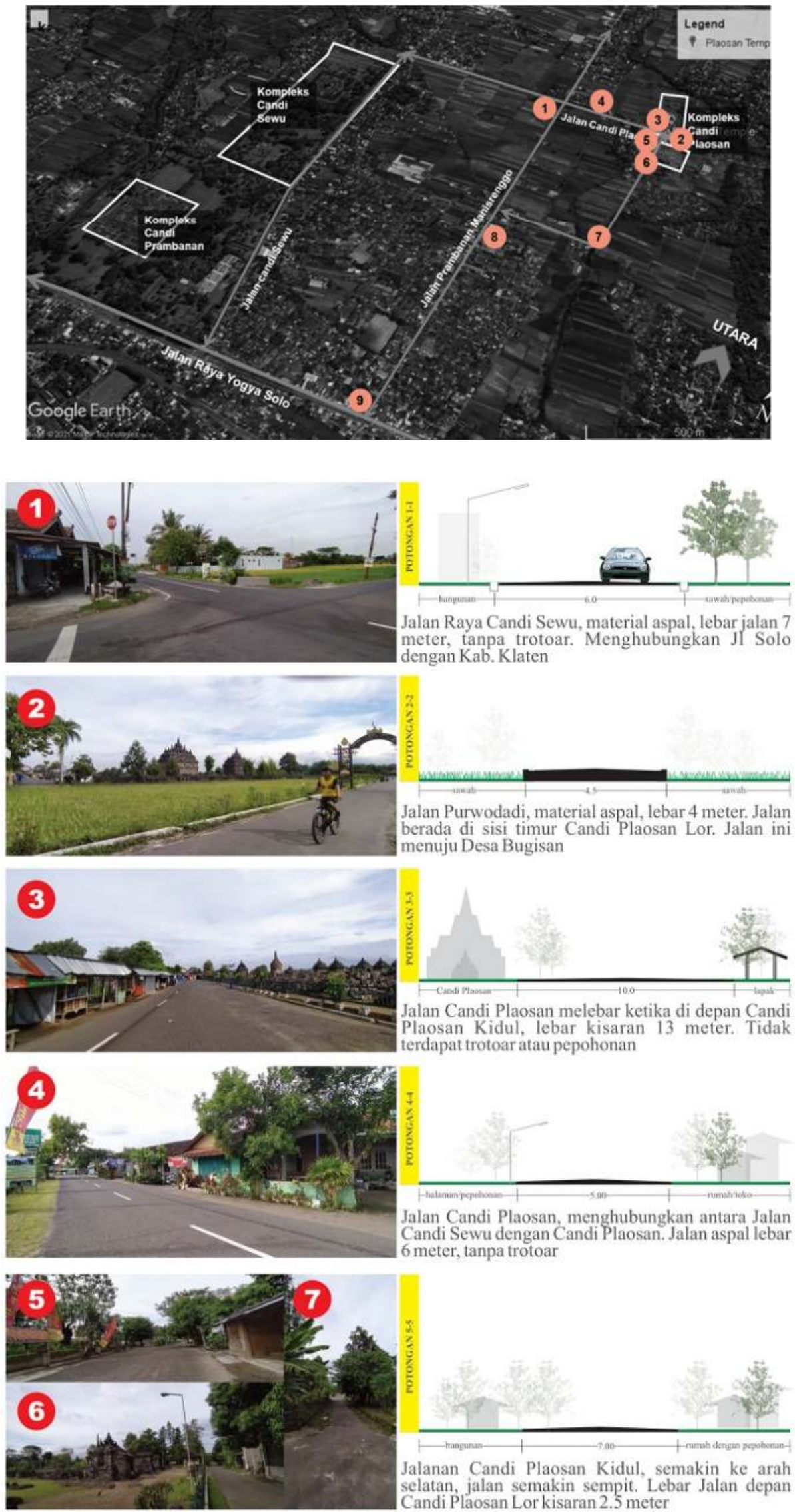

Jalanan Candi Plaosan Kidul, semakin ke arah selatan, jalan semakin sempit. Lebar Jalan depan

Gambar 7 hasil amatan aksesibilitas 
Permasalahan terhadap pencapaian menuju Kompleks Candi Plaosan adalah minimnya penanda untuk mencapai kawasan.
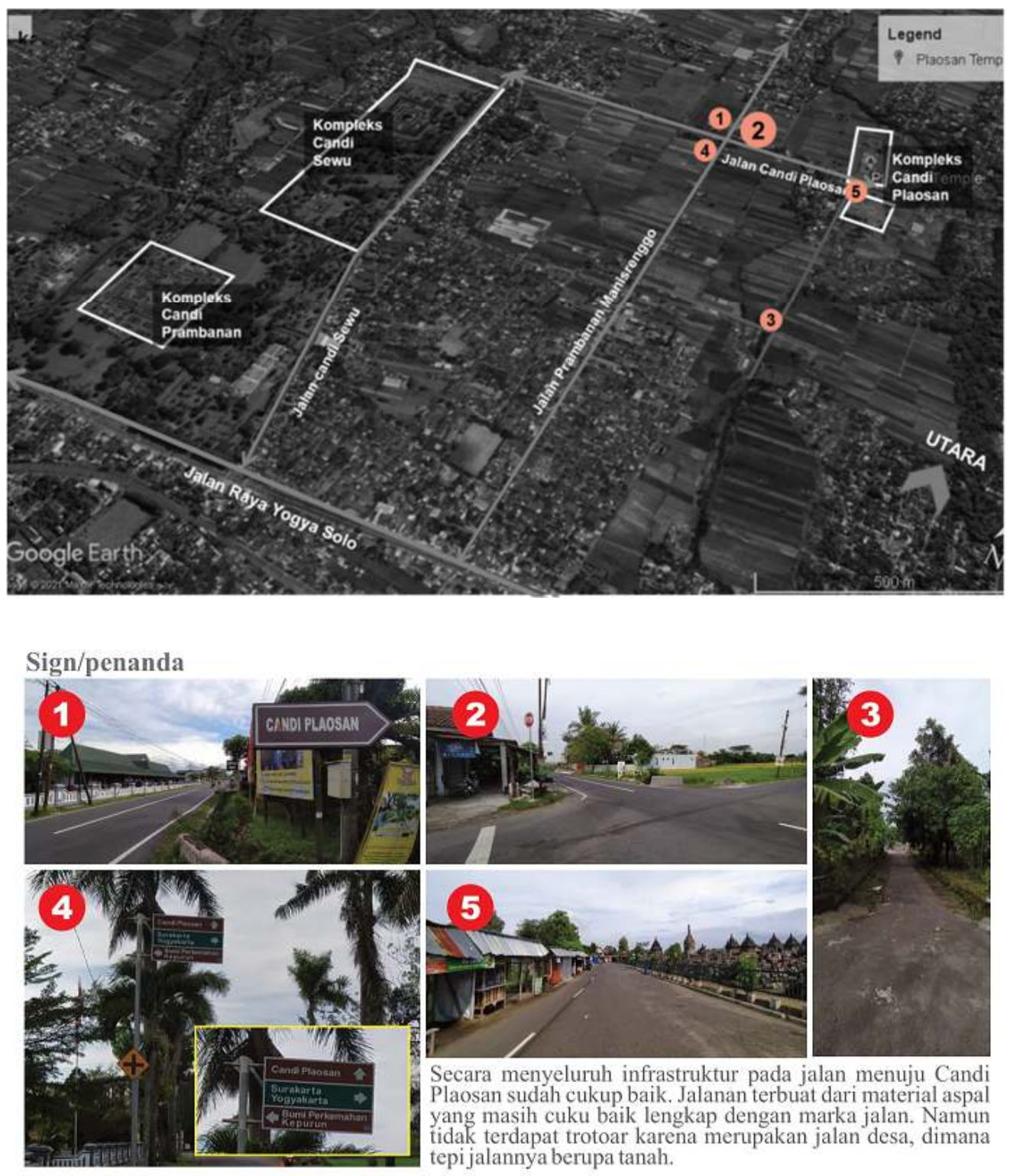

Gambar 8. Penanda (signage) di sepanjang akses menuju kawasan wisata Candi Plaosan

Sebuah penanda setidaknya dapat menginformasikan dengan baik salah satunya dari aspek visual lingkungan perkotaan (imageability) sehingga dapat menciptakan makna dari lingkungan tersebut.
Untuk Sarana Transportasi umum hanya sampai di simpang jalan Raya Yogya-Solo, kemudian hanya terdapat tukang ojek, atau becak. Sehingga wisatawan lebih cenderung menggunakan kendaraan pribadi.

Table 4. Kemudahan pencapaian

\begin{tabular}{|c|c|c|c|}
\hline \multicolumn{4}{|c|}{ Kemudahan Pencapaian } \\
\hline $\begin{array}{l}\text { Signage/ } \\
\text { penanda }\end{array}$ & & Ada Terbatas & $\begin{array}{l}\text { Hanya berada pada simpang menuju jalan } \\
\text { Plaosan dengan desain yang belum }\end{array}$ \\
\hline Jarak & & $\begin{array}{l}\text { Semakin dekat dari pusat } \\
\text { kegiatan semakin baik }\end{array}$ & $2 \mathrm{~km}$ dari jalan Utama Yogya-Solo \\
\hline Dimensi dan Material & & Sesuai/tidak dengan standar & Sesuai, masih tersedia ruang di kanan kiri jalan \\
\hline $\begin{array}{l}\text { Ketersediaan } \\
\text { transportasi Umum }\end{array}$ & Sarana & Ada terbatas & Tukang ojek dan Becak \\
\hline
\end{tabular}




\subsection{Kemenarikan Jalur}

Pada sepanjang akses pencapaian dari pusat kota (simpang jalan Raya Yogya-Solo) menuju kawasan wisata Candi Plaosan sejauh $2 \mathrm{~km}$, hanya ditemui penerangan jalan berupa lampu jalan. Elemen ruang jalan lain belum dapat ditemui dengan baik.
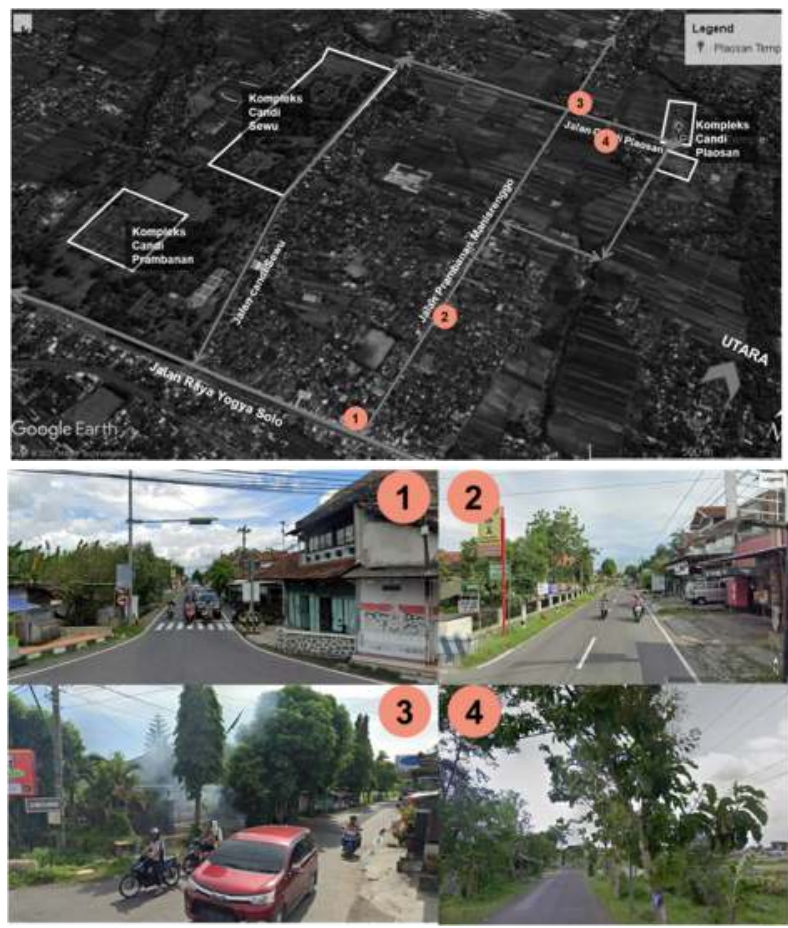

Gambar 9. Susana Aksesibilitas di sepanjang kawasan wisata Candi Plaosan

Table 5. Kemenarikan Jalur

\begin{tabular}{|c|c|c|}
\hline \multicolumn{3}{|c|}{ Kemenarikan Jalur (attractiveness) } \\
\hline Street Furniture & Ada terbatas & Lampu penerangan jalan dari pemerintah \\
\hline Jalur Pedestrian & Ada/tidak terhubung/terputus & Tidak terdapat jalur pedestrian \\
\hline Material dan warna & Ada/tidak & Tidak ada \\
\hline Vitalitas Kawasan & $\begin{array}{l}\text { Ada/tidak aktivitas pada ruang } \\
\text { jalan, pejalan kaki, PKL, Dll) }\end{array}$ & $\begin{array}{l}\text { Pejalan kaki tidak banyak ditemui, ada tetapi tidak berkaitan } \\
\text { dengan aktivitas wisata }\end{array}$ \\
\hline & & $\begin{array}{c}\text { PKL ada, banyak ditemui mendekati Candi Plaosan. } \\
\text { Aktivitas lain tidak ditemui }\end{array}$ \\
\hline Vegetasi peneduh & Ada/tidak & Ada terbatas \\
\hline
\end{tabular}

\subsection{Legibilitas}

Legibilitas adalah kejelasan terhadap suatu objek baik itu berupa elemen ruang ataupun karakter ruang itu sendiri. Membaca visual memalui warna, bentuk dan elemen lain yang dapat ditangkap oleh pengamat untuk membentuk identitas [10]. Pada Aksesibilitas kawasan Candi Plaosan, kejelasan belum tampak. Penanda masih belum terlihat jelas, sepanjang koridor juga masih belum mencirikan karakter ruang kawasan.

Table 6. Legibilitas Candi

\begin{tabular}{lll}
\hline & & \multicolumn{1}{c}{ Legibilitas } \\
\hline Titik Masuk/ Gerbang & Ada/Tidak & Ada terbatas, desain belum terlihat jelas. \\
Signage/penanda & Ada/tidak & Hanya berada pada simpang menuju jalan Plaosan dengan desain yang belum \\
Titik berhenti (nodes) & Ada/tidak & Tidak ada \\
Identity/ & Kuat/tidak & Belum kuat \\
karakter ruang & & Desain masih secara umum. \\
\hline
\end{tabular}




\subsection{Path, Portal, Place dalam strategi penguat karakter Aksesibilitas Wisata Candi Plaosan}

Beberapa karakter penguat aksesibilitas Wisata Candi Plaosan ditampilkan pada Tabel 7.

Tabel 7. Karakteristik penguat aksesibilitas Wisata Candi Plosan

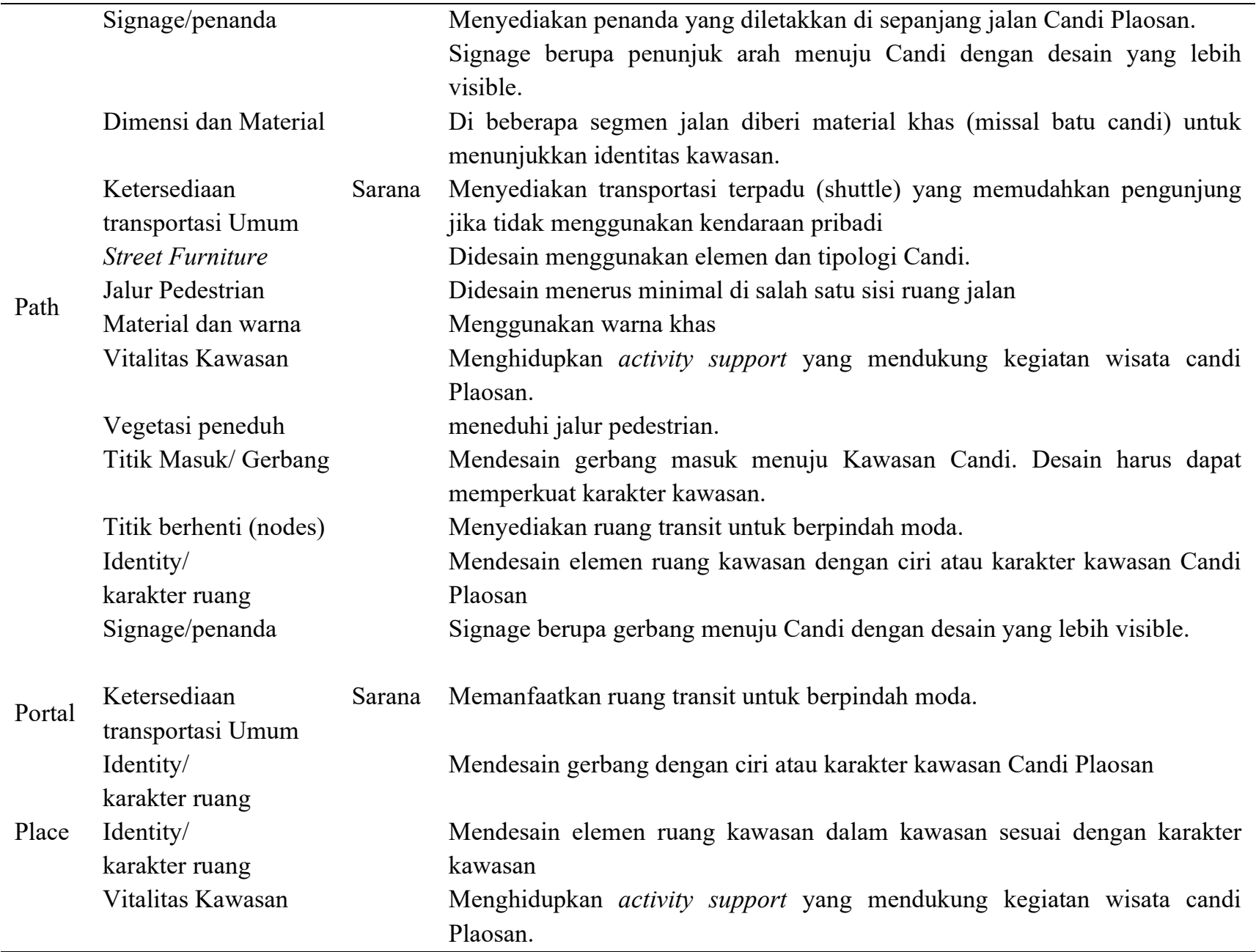

\section{Simpulan}

Aksesibilitas merupakan salah satu elemen yang menguatkan keberhasilan sebuah Kawasan Wisata. Untuk penguatan Aksesibilitas pada kawasan Wisata Candi Plaosan dapat digunakan strategi path, portal, place. Path akan menjadi strategi untuk menguatkan karakter kawasan wisata, yang berkaitan dengan desain penanda, dimensi dan material, sarana transportasi, street furniture, jalur pedestrian, material warna, vitalitas kawasan, vegetasi peneduh, titik masuk dan berhenti, dan identitas kawasan. Portal berupa gerbang masuk kawasan Candi yang diletakkan tepat di titik masuk candi. Sedangkan Place, terkait dengan Kawasan Inti Candi (plaosan Lor dan Kidul). Kawasan inti Candi secara setting fisik dan aktivitasnya harus menjadi daya tarik yang mencirikan karakter ruang Kawasan Wisata Candi Plaosan.

\section{Daftar Rujukan}

[1] D. Di. kebudayaan kementrian Pendidikan dan kebudayaan, "Pariwisata Budaya untuk Pelestarian Cagar Budaya." .

[2] P. Kabupaten, Rencana Tata Ruang Wilayah Kabupaten Klaten tahun 2011-2031. 2011.

[3] D. F. Indriyani, P. S. Geografi, F. Geografi, and U. M. Surakarta, "Obyek Wisata Candi Di Kabupaten Klaten Jawa Tengah Tahun 2018,” 2018.

[4] F. Noverianto, "Analisis Kebutuhan Sarana Dan Prasarana Penunjang Pariwisata di Desa Sembungan,Kecamatan Kejajar Kabupaten Wonosobo," 2018.

[5] S. Abdulhaji and I. S. H. Yusuf, "Pengaruh atraksi, aksesibilitas, dan fasilitas terhadap citra objek wisata danau tolire besar di kota ternate," Humano: Jurnal Penelitian, vol. 7, no. 2, pp. 134-148, Mar. 2017, doi: 10.33387/HJP.V7I2.317.

[6] H. Shirvani, The Urban Design Process. New York: Van Nostrand Reinhold, 1985.

[7] D. Carmona, Matthew, Urban Design Reader. 
Architectural Press is an inprint of Elsevier Linacre House, Jordan Hill, Oxford OX2 8 DP, UK., 2007.

[8] K. Lynch, The Image Of The City. The M.I.T. Press, 1975.

[9] D. Ratriningsih, "Arahan penataan kampung tradisional wisata batik kauman surakarta," Inersia : Jurnal Teknik Sipil dan Arsitektur, vol. 13, no. 2, pp.
116-128, Dec. 2017, doi: 10.21831/INERSIA.V13I2.17175.

[10]B. A. Nugroho, "Identitas Kota: Pembangunan Imaji Kota melalui Karya Seni di Ruang Publik," Jurnal Rupa, vol. 3, no. 1, p. 44, 2018, doi: 10.25124/rupa.v3i1.1328. 